\title{
Maternal and umbilical homocysteine in preeclampsia
}

\author{
MIRNA VUKOVIĆ BOBIĆ1 \\ JASNA ČERKEZ HABEK ${ }^{2}$ \\ DUBRAVKO HABEK ${ }^{3}$ \\ ${ }^{1}$ Kaiser Franz Josef Hospital, SMZ-Süd, Department \\ of Obstetrics and Gynecology, Vienna, Austria \\ ${ }^{2}$ Department of Cardiology, Clinical Department of \\ Internal Diseases, Sveti Duh University Hospital, \\ Croatian Catholic University, Zagreb, Croatia \\ ${ }^{3}$ Clinical Department of Obstetrics and Gynecology, \\ Sveti Duh University Hospital, Croatian Catholic \\ University, Zagreb, Croatia
}

\section{Correspondence:}

Prof. Dubravko Habek, MD, MSc, PhD, PhD

University Department of Obstetrics and Gynecology, University Hospital "Sveti Duh",

Sveti Duh 64 Street, Croatian Catholic University, 10000 Zagreb, Croatia

e-mail:dubravko.habek@os.t-com.hr

Key words: preeclampsia, homocysteine, maternal blood, umbilical blood

Received November 09, 2015

Revised April 14, 2016.

Accepted April 18, 2016

\section{Abstract}

Background and purpose: Were to assess the association between homocysteine levels and development of preeclampsia, to determine homocysteine levels in fetal circulation, to differentiate homocysteine levels in mild and severe preeclampsia and to compare homocysteine levels in pregnant women with preeclampsia with homocysteine levels measured in the same group of women six months after delivery.

Material and methods: The study included 55 pregnant women with mild or severe preeclampsia (hypertensia with proteinuria), while control group of 50 healthy pregnant women. Maternal and umbilical blood homocysteine levels were determined by the fluorescence polarization immunoassay. Shapiro-Wilks, Mann-Whitney and Wilcoxon statistical tests performed for statistical analysis.

Results: In women with preeclampsia, the mean homocysteine level was by 0.744 umol/L higher than in control women; with mild preeclampsia, the level was by $2.752 \mu \mathrm{mol} / \mathrm{L}$ lower as compared to the women with severe preeclampsia $(p<0.0001)$. In women with preeclampsia, the mean umbilical blood homocysteine level was by $0.268 \mu \mathrm{mol} / \mathrm{L}$ lower than the respective level measured in control group $(p<0.0001)$. In women with preeclampsia, the mean homocysteine level was by $0.878 \mu \mathrm{mol} / \mathrm{L}$ lower in the same group of women six months after delivery $(p<0.0001)$.

Conclusion: Homocysteine are lower in preeclamptic women six months after delivery. The neonates born to mothers with preeclampsia are not at a higher exposure to homocysteine.

\section{INTRODUCTION}

Since the 1990s, homocysteine has been associated with disorders of the fetomaternal unit (1). Studies on recurrent abortions also found clear association between elevated homocysteine levels and the risk of abortion (2,3). Later on, Vollset et al. (4) found the levels of homocysteine to be associated with the prevalence of preeclampsia, preterm delivery, low birth weight, intrauterine growth restriction (IUGR), stillbirth, congenital malformations and abruptio placentae. The association of mild hyperhomocysteinemia with cardiovascular disease and related mortality was demonstrated in a number of studies (5-11).

Hyperhomocysteinemia alters vascular morphology, stimulates inflammation, activates endothelium and blood clotting cascade, and inhibits fibrinolysis. Hyperhomocysteinemia results in the loss of endothelial antithrombin function and induction of a procoagulant setting $(9,12)$. The pathogenetic action of homocysteine also includes interference with the nitric oxide (NO) system (homocysteine reduces NO bioavailability by interfering with its synthesis), activation of transcrip- 
tion factors stimulating gene expression (activation of sterol-regulatory element-binding protein $(S R E B P)$ and protein kinase $\mathrm{C}$ (PKC), lipid biosynthesis), chemotaxis and leukocyte adhesion (sICAM-1, VCAM-1, interleukin-8, von Willebrand's factor) $(13,14)$.

The aims of the study were to assess the association between elevated homocysteine levels and development of preeclampsia; to determine homocysteine levels in fetal circulation; to differentiate homocysteine levels in mild and severe preeclampsia; and to compare homocysteine levels in pregnant women with preeclampsia with homocysteine levels measured in the same group of women six months after delivery.

\section{METHODS}

The study included 55 pregnant women with verified milde preeclampsia (blood pressure measured on two occasions at least $4 \mathrm{~h}$ apart $\geq 140 / 90 \mathrm{~mm} \mathrm{Hg}$ after $20^{\text {th }}$ week of gestation, and positive proteinuria) and severe preeclampsia (blood pressure $\geq 160 / 110 \mathrm{~mm} \mathrm{Hg}$, proteinuria $\geq++)$. Control group consisted of 50 healthy pregnant women, as approved by the Ethics Committee of the Osijek University Hospital. All pregnant women are taking folate supplements and vitamins, including B6 and B12 during pregnancy and puerperium (Elevit ${ }^{\circ}$, Bayer, Germany). In both preeclampsia and control group, homocysteine levels were measured after at least 12-h fasting. Umbilical blood homocysteine levels were determined in the same groups of women after delivery, during third stage. In the group of women with preeclampsia, blood homocysteine was also determined six months after delivery. Homocysteine levels were determined by the FPIA (fluorescence polarization immunoassay) technology on an AxSYM device (Abbott Laboratories) using reagents of the same manufacturer (Testkit Code No. 5F51-20). According to Khong and Hague (15), hyperhomocysteinemia is present in pregnant women when the level of homocysteine exceeds $10.9 \mu \mathrm{mol} / \mathrm{L}$.

On statistical analysis, the basic characteristics of the sample consisting of women with preeclampsia and control women were determined first. Because of the relatively small number of study subjects, the Shapiro-Wilks test, t-test for dependent variables and Levene's test were used. When the Shapiro-Wilks test failed to confirm the hypothesis of normal distribution, Mann-Whitney and Wilcoxon tests were employed. Differences confirmed at the level of $p<0.05$ were considered to be statistically significant. Data were prepared by use of the Microsoft Excel calculator, while the SPSS and Statistica packages were used on data processing. Box and Whisker Plot diagrams were done by the Statistica application because the reasons stated statistical data processing.

\section{RESULTS}

Age and parity in two groups were no statistic significantly, but gestational age in preeclamptic women are shortly 35,5 vs 39,1 weeks $(p<0,0001)$ because high number induced and preterm delivery.

In women with preeclampsia, the mean homocysteine level was $6.758 \mu \mathrm{mol} / \mathrm{L}$. According to median, the mean level of homocysteine was $\leq 6.4 \mu \mathrm{mol} / \mathrm{L}$ and $\geq 6.4 \mu \mathrm{mol} / \mathrm{L}$ in $50 \%$ of women with preeclampsia each. In control group, the mean homocysteine level was $6.014 \mu \mathrm{mol} / \mathrm{L}$. According to median, the mean homocysteine level was $\leq 5.8 \mu \mathrm{mol} / \mathrm{L}$ and $\geq 5.8 \mu \mathrm{mol} / \mathrm{L}$ in $50 \%$ of control women each. The lowest and highest homocysteine level was 2.6 $\mu \mathrm{mol} / \mathrm{L}$ and $9.8 \mu \mathrm{mol} / \mathrm{L}$, respectively, yielding a range of variation of $7.2 \mu \mathrm{mol} / \mathrm{L}$ (Figure 1). In preeclampsia group, the mean homocysteine level was greater by $0.744 \mu \mathrm{mol} / \mathrm{L}$ and the median calculated for these women by $0.6 \mu \mathrm{mol} / \mathrm{L}$ than the respective values recorded in control group. The Mann-Whitney test indicated nonexistence of statistically significant differences in homocysteine levels between the group of women with preeclampsia and control group $(\mathrm{Z}=-1.733, \mathrm{p}=0.083)$. In women with mild preeclampsia, the mean homocysteine level was 6.008 $\mu \mathrm{mol} / \mathrm{L}$. The lowest and highest homocysteine level was $3.9 \mu \mathrm{mol} / \mathrm{L}$ and $8.6 \mu \mathrm{mol} / \mathrm{L}$, respectively, yielding a range of variation of $4.7 \mu \mathrm{mol} / \mathrm{L}$. In women with severe preeclampsia the mean homocysteine level was 8.760 $\mu \mathrm{mol} / \mathrm{L}$. According to median, the mean homocysteine level was $\leq 8.6 \mu \mathrm{mol} / \mathrm{L}$ and $\geq 8.6 \mu \mathrm{mol} / \mathrm{L}$ in $50 \%$ of women with severe preeclampsia each. In women with mild preeclampsia, the mean homocysteine level was by 2.752 $\mu \mathrm{mol} / \mathrm{L}$ lower than the mean homocysteine level recorded in women with severe preeclampsia, whereas the median

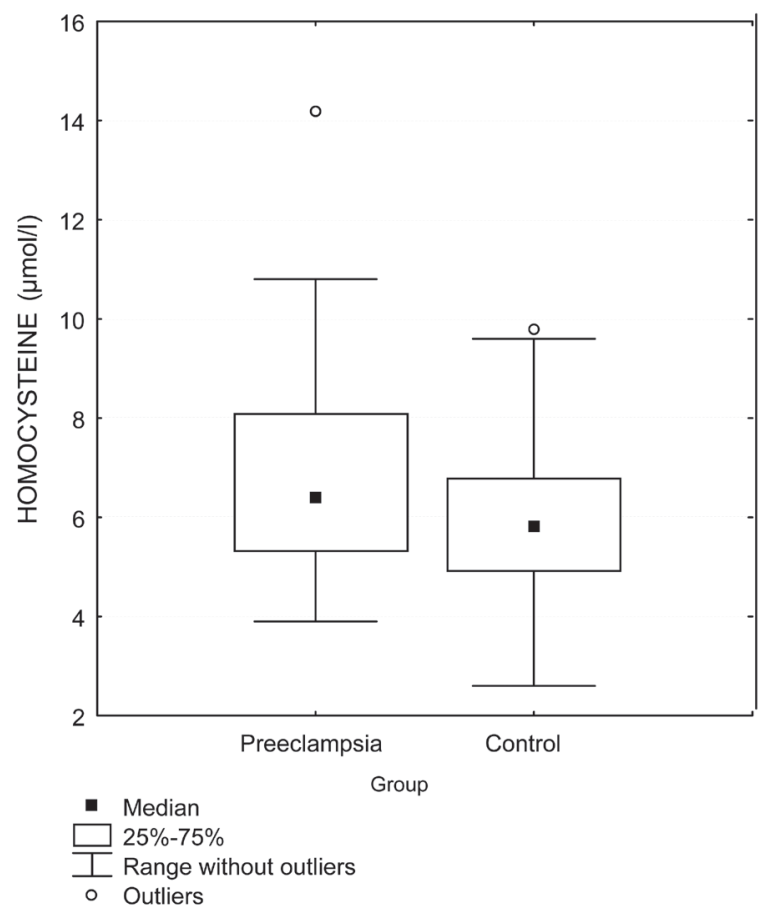

Figure 1. Box and Whisker Plot diagram of variables defined as homocysteine level in women with preeclampsia and control women. 


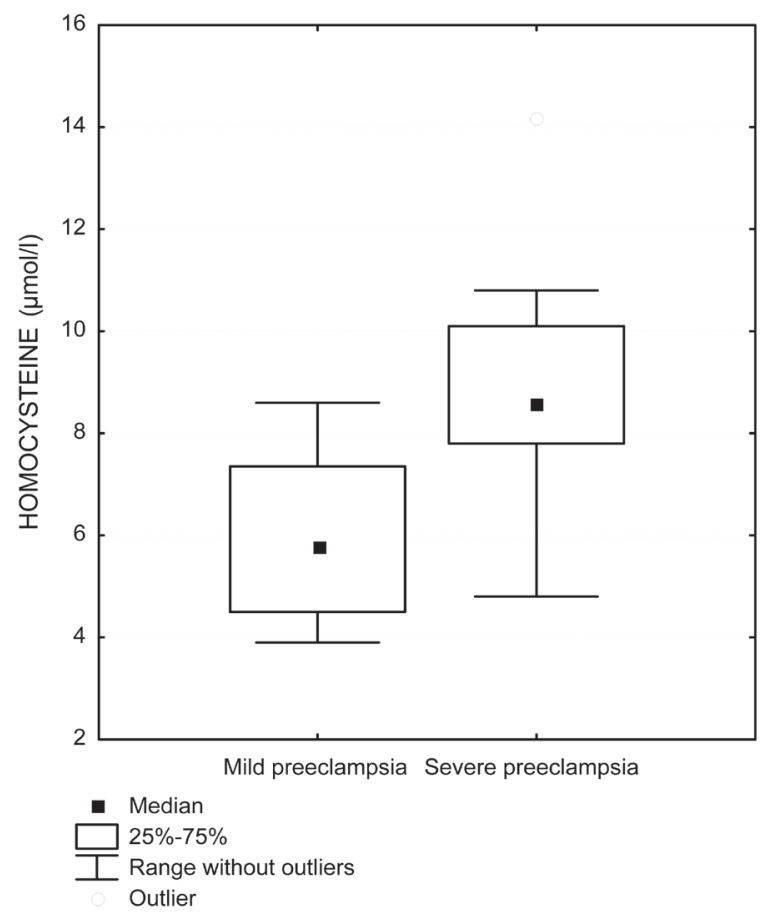

Figure 2. Box and Whisker Plot diagram of variables defined as homocysteine level in women with mild preeclampsia and severe preeclampsia.

calculated for women with mild preeclampsia was lower by $2.8 \mu \mathrm{mol} / \mathrm{L}$ (Figure 2). Mann-Whitney test yielded a statistically significant difference in homocysteine level

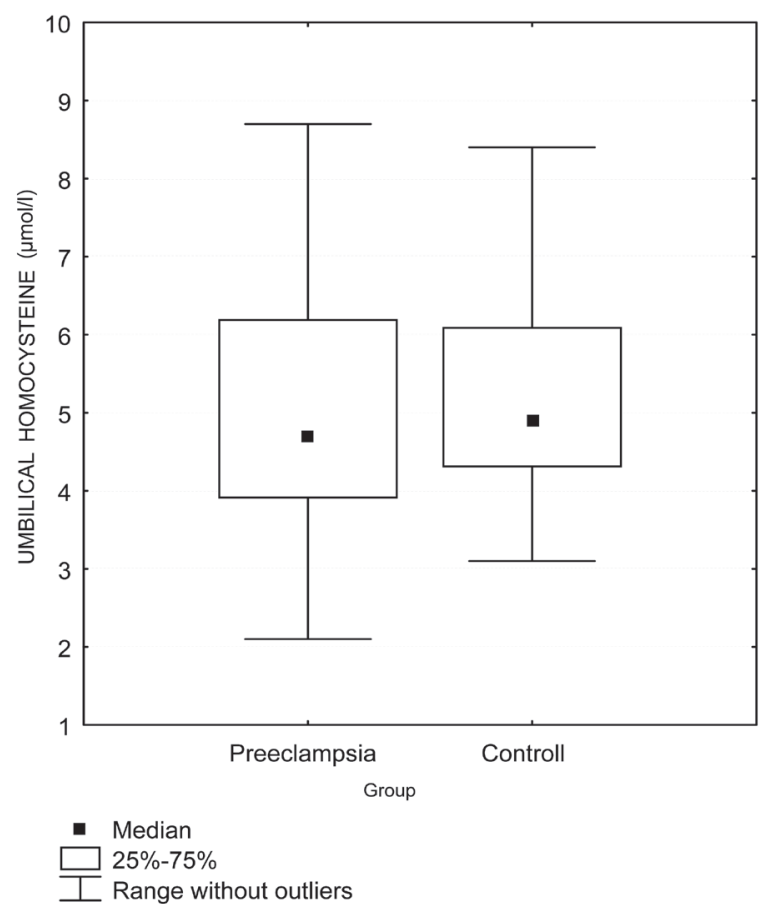

Figure 3. Box and Whisker Plot diagram of variables defined as umbilical homocysteine level in women with preeclampsia and control women. between pregnant women with mild preeclampsia and those with severe preeclampsia $(Z=-4.199, \mathrm{p}<0.0001)$.

In the neonates born to mothers with preeclampsia and those born to mothers from control group, the mean level of umbilical homocysteine was $5.044 \mu \mathrm{mol} / \mathrm{L}$ and 5.312 $\mu \mathrm{mol} / \mathrm{L}$, respectively (Figure 3 ). In women with preeclampsia, the mean homocysteine level was by $0.268 \mu \mathrm{mol} / \mathrm{L}$ lower than the respective level measured in control women, while the median calculated for women with preeclampsia was lower by $0.2 \mu \mathrm{mol} / \mathrm{L}$. Spearman's rank correlation coefficient between maternal and umbilical homocysteine yielded a moderately positive statistically significant correlation (?? $=0.670, \mathrm{p}<0.0001)$. In women with preeclampsia, the mean homocysteine level was $6.758 \mu \mathrm{mol} / \mathrm{L}$. According to median, the mean homocysteine level was $\leq 6.4 \mu \mathrm{mol} / \mathrm{L}$ and $\geq 6.4 \mu \mathrm{mol} / \mathrm{L}$ in $50 \%$ of women with preeclampsia each. The mean homocysteine level measured in women with preeclampsia six months after delivery was 7.636 $\mu \mathrm{mol} / \mathrm{L}$ (Figure 4). In pregnant women with preeclampsia, the mean homocysteine level was lower by $0.878 \mu \mathrm{mol} / \mathrm{L}$ and the median calculated for these women by $1.3 \mu \mathrm{mol} / \mathrm{L}$ than the respective figures recorded six months after delivery. Wilcoxon test yielded a statistically significant difference in homocysteine level in preeclampsia women before and after delivery $(Z=-3.604, p<0.0001)$.

\section{DISCUSSION}

The pattern of the amino acid homocysteine behavior in preeclampsia has been investigated in many studies,

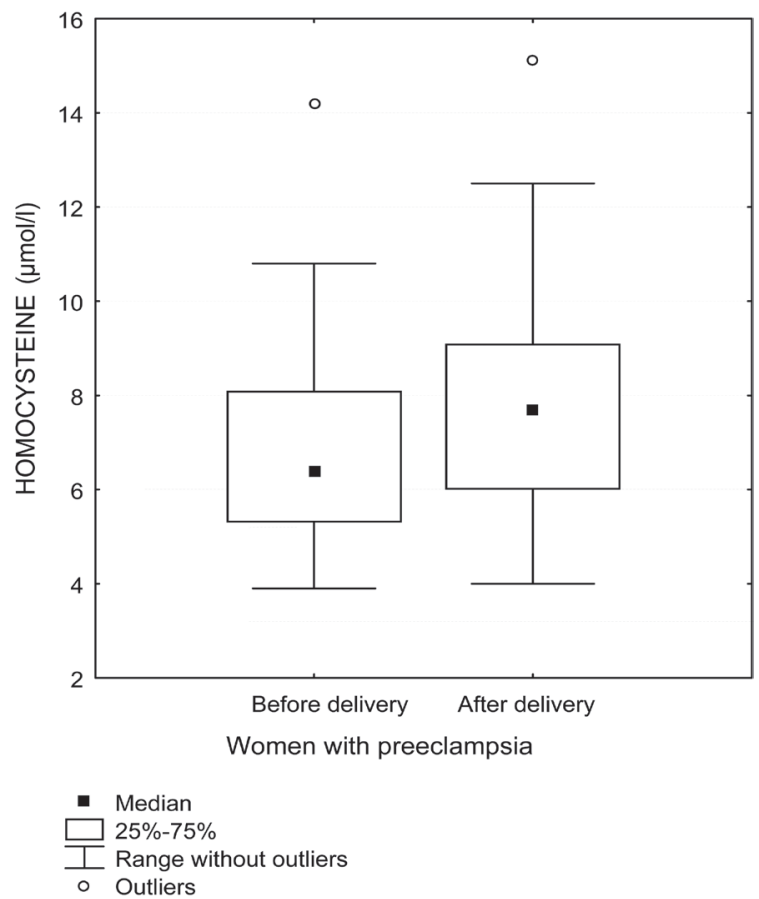

Figure 4. Box and Whisker Plot diagram of variables defined as homocysteine level in women with preeclampsia before and after delivery. 
with sharply opposed results. In the study by Powers et al. (16), the mean homocysteine levels were significantly elevated $(\mathrm{p}<0.04)$ in women with preeclampsia as compared with control group $(9.7 \mu \mathrm{mol} / \mathrm{L}$ vs. $7.0 \mu \mathrm{mol} / \mathrm{L})$. Similar results $(6.7 \mu \mathrm{mol} / \mathrm{L}$ vs. $3.8 \mu \mathrm{mol} / \mathrm{L} ; \mathrm{p}<0.01)$ have also been reported by Laviouri et al. (17). These two studies were of a similar design, conducted in a sample of 50 primiparae; however, in the former study, blood samples were obtained before delivery after 6-hour fasting, whereas in the latter blood samples were collected during third trimester after at least 12-hour fasting. Therefore, differences in the mean homocysteine levels could be ascribed to variation in sampling time. Rajkovic et al. (18) conducted a study on African women and found the risk of developing preeclampsia to be 4.57 -fold greater $(\mathrm{OR}=4.57 .2 ; 95 \% \mathrm{CI}$ : 2.11-9.88) in women with higher homocysteine levels, whereas Sorensen et al. (19) demonstrated the respective risk to be 3.2-fold greater (OR=3.2; 95\% CI: 1.11-9.2). The latter two studies showed the risk to increase significantly in primiparae in comparison with multiparae with comparable homocysteine levels. The risk was 12.9-fold greater in African primiparae (OR=12.9; 95\%CI: 5.2831.53) and 9.7-fold greater in American primiparae (OR=9.7; 95\%CI: 2.1-14). Both studies were adjusted for various confounding factors by multivariate analysis. Variations between the studies could be attributed to differences in the number of study subjects (more than double in the former study) and the time of blood sampling because it was performed after delivery in African women and in second trimester in American women. Our results showed the mean homocysteine level $(6.758 \pm 2.062$ $\mu \mathrm{mol} / \mathrm{L})$ and median $(6.400 \mu \mathrm{mol} / \mathrm{L})$ calculated for women with preeclampsia to exceed the respective values recorded in the control group of women free from preeclampsia $(6.014 \pm 1.539 \mu \mathrm{mol} / \mathrm{L}$ and $5.800 \mu \mathrm{mol} / \mathrm{L})$; however, the between-group difference in homocysteine levels did not reach statistical significance. Makedos et al. (20) compared homocysteine levels in a group of pregnant women with preeclampsia and control group free from preeclampsia and found the mean homocysteine level to be significantly increased in the former $(11.11 \mu \mathrm{mol} / \mathrm{L} v \mathrm{~s}$. $6.40 \mu \mathrm{mol} / \mathrm{L}, \mathrm{p}<0.001)$. There was no between-group difference in the folic acid and vitamin B12 levels. The group of women with preeclampsia was associated with a higher rate of cesarean section, IUGR (50\%) and abruptio placentae (20).

Malinow et al. (21) investigated the relationship of homocysteine levels in maternal venous blood, umbilical vein and umbilical artery and found a decreasing concentration gradient with $1 \mu \mathrm{mol} / \mathrm{L}$ difference for each of the samples tested. The mean homocysteine level in maternal plasma was $5.43 \pm 1.40 \mu \mathrm{mol} / \mathrm{L}$, by approximately 1 $\mu \mathrm{mol} / \mathrm{L}$ greater than the mean homocysteine level in umbilical vein $(4.49 \pm 1.78 \mu \mathrm{mol} / \mathrm{L})$. These authors also report on positive correlation between umbilical homocysteine (umbilical artery and umbilical vein) and maternal plasma homocysteine. Based on these results, they suggest the possibility of transplacental transfer of maternal homocysteine to the umbilical vein, thus being incorporated in the fetal metabolic cycle. These authors also found negative correlation of maternal homocysteine with gestational age and neonatal birth weight, and explain it by fetal utilization of homocysteine proportionate to fetal weight and gestational age (21). These results explain the homocysteine decline in normal pregnancy $(21,22)$. Similar results were also recorded in the present study; however, in the group of pregnant women with preeclampsia, the mean homocysteine level was lower than the respective level measured in the same group of women six months after delivery, the difference being statistically significant.

In contrast to the studies mentioned above but similar to our results, Mignini et al. (23) published results of a systematic review that included 25 studies, 8 and 17 of which measured serum homocysteine levels before and after the onset of preeclampsia, respectively. In many of these studies, differences in the mean homocysteine levels according to gestational age were recorded both in normal pregnancy and in women with preeclampsia, especially those with severe preeclampsia (mean difference: 1.42 $\mu \mathrm{mol} / \mathrm{L}, 95 \% \mathrm{CI}$ : 0.53-2.30), unlike women with mild preeclampsia (mean difference: $0.60 \mu \mathrm{mol} / \mathrm{L}, 95 \% \mathrm{CI}$ : 0.30-0.89). These biological gradients were not statistically significant.

The investigators analyzed the possible etiologic factors of hyperhomocysteinemia (folate and vitamin B12 levels and genetic polymorphisms) and found no association with hyperhomocysteinemia. Then they assessed the possible effect of hyperhomocysteinemia on the development of preeclampsia via oxidative stress and endothelial dysfunction, as we also postulated in our study, and found the studies reviewed to report divergent input and poor correlation of the factors assessed, i.e. absence of biological plausibility; therefore, they consider that the association of hyperhomocysteinemia and preeclampsia cannot be explained by the current literature data (23). In contrast to the study by Mignini et al. (23), a more recent report by Acilmis et al. (24) offers an explanation of the obscurities related to hyperhomocysteinemia and pregnancy by differentiating severe and mild preeclampsia. They monitored the levels of homocysteine, folic acid and vitamin B12 in three groups of pregnant women, i.e. severe preeclampsia, mild preeclampsia and normal pregnancy, and found statistically significantly higher homocysteine levels in maternal and fetal (umbilical) blood in the group of women with severe preeclampsia as compared with the groups of women with normal pregnancy and those with mild preeclampsia. There was no statistically significant difference in the levels of maternal and fetal (umbilical) homocysteine between the groups of women with normal pregnancy and those with mild preeclampsia. There was no statistically significant betweengroup difference in folic acid and vitamin B12 levels in 
maternal and fetal (umbilical) samples either. The authors conclude that the levels of homocysteine are significantly higher in the group of women with severe preeclampsia as compared with the groups of women with mild preeclampsia and those with normal pregnancy, suggesting that the increased homocysteine levels may be associated with the severity of preeclampsia. They also consider that elevated homocysteine levels do not appear to be accompanied by folic acid and vitamin B12 deficiency (24). A similar homocysteine pattern was also observed in our study. Subdivision of our group of pregnant women according to the severity of preeclampsia based on the criteria of blood pressure $\geq 160 / 110 \mathrm{~mm} \mathrm{Hg}$ and proteinuria $\geq++(10 \mathrm{mg} / \mathrm{dL})$ yielded two subgroups of women (15 with severe preeclampsia and 40 with mild preeclampsia) that differed significantly according to the mean homocysteine levels. In the subgroup of women with severe preeclampsia, the mean homocysteine level $(8.760 \pm 2.156$ $\mu \mathrm{mol} / \mathrm{L})$ and median $(8.6 \mu \mathrm{mol} / \mathrm{L})$ exceeded the respective values recorded in women with mild preeclampsia $(6.008 \pm 1.449 \mu \mathrm{mol} / \mathrm{L}$ and $5.8 \mu \mathrm{mol} / \mathrm{L}$, respectively). White et al. proven of differences in homocysteine levels between the subgroups were also statistically significant. A history of hypertension in pregnancy, when compared with normotensive pregnancy, was associated with a $4.5 \%$ higher serum homocysteine level and 1.60-fold increased odds of having an elevated after adjusting for potentially confounding covariates. Aa history of normotensive pregnancy, as compared with nulliparity, was associated with a $6.1 \%$ lower serum homocysteine level and a 0.49 -fold reduced odds of elevated homocysteine levels (25). Other recently investigations they found significantly higher values umbilical homocysteine in womens with severe preeclampsia, but without only indicate some degree of in-utero fetal cardiac cell damage (26).

Our results suggested that there was no difference in homocysteine levels between normal pregnancies and pregnancies complicated by preeclampsia, but homocysteine levels in women with preeclampsia were statistically significantly lower than homocysteine levels measured in the same group of women six months after delivery. In women with severe preeclampsia, homocysteine levels exceeded those in women with mild preeclampsia. However, our study results yielded no statistical evidence for the infants born to mothers with preeclampsia to be at a higher exposure to homocysteine than those born to mothers with normal pregnancy.

\section{REFERENCES}

1. MRC Vitamin Study Research Group 1991 Prevention of neural tube defects: results of the Medical Research Council Vitamin study. Lancet 338:131-136.

http://dx.doi.org/10.1016/0140-6736(91)90133-A

2. STEEGERS-THEUNISSEN RPM, BOERS GHJ, BLOM HJ, TRIJBELS FJM, ESKERS TKAB 1992 Hyperhomocysteinemia and recurrent spontaneous abortion or abruptio placentae. Lancet 339:112-113. http://dx.doi.org/10.1016/0140-6736(92)90725-I
3. NELEN WLDM, BLOM HJ, STEEGERS EAP, DEN HEIJER M, THOMAS CMG, ESKERS TKAB 2000 Homocysteine and folate levels as risk factors for recurrent early pregnancy loss. Obstet Gynecol 95:519-524.

http://dx.doi.org/10.1097/00006250-200004000-00009

4. VOLLSET SE, REFSUM H, IRGENS LM, EMBLEM BM, TVERDALl A, GJESSING HK 2000 Plasma total homocysteine, pregnancy complications, and adverse pregnancy outcomes: the Hordaland Homocysteine Study. Am J Nutr 71:962-968.

5. CHEN P, PODDAR R, TIPAEV, DIBELLO PM, MORAVEC CD, ROBINSON K 1999 Homocysteine metabolism in cardiovascular cells and tissues: implications for hyperhomocysteinemia and cardiovascular disease. Adv Enzyme Regul 39:93-109.

6. CLARKE R, DALY L, ROBISNON K, NAUGHTEN E, CAHALANE S, FOWLER B 1991 Hyperhomocysteinemia: an independent risk factor for vascular disease. N Engl J Med 324:1149-1155. http://dx.doi.org/10.1056/NEJM199104253241701

7. CLARKE R, SHIPLEY M, LEWINGTON S, YOUNGMAN L, COLLINS R, MARMOT M 1999 Underestimation of risk associations due to regression dilution in long-term follow-up of prospective studies. Am J Epidemiol 150:341-353.

http://dx.doi.org/10.1093/oxfordjournals.aje.a010013

8. GRAHAM I 1999 Homocysteine in health and disease. Ann Intern Med 131:387-388.

http://dx.doi.org/10.7326/0003-4819-131-5-199909070-00010

9. HERRMANN W, SCHORR H, BODIS M, KNAPP JP, MULLER A, STEIN G, GEISEL J 2000 Role of homocysteine, cystathione and methylmalonic acid measurements for diagnosis of vitamin deficiency in high-aged subjects. Eur J Clin Invest 30:1083-1089. http://dx.doi.org/10.1046/j.1365-2362.2000.00746.x

10. HILL AB 1965 The enviroment and disease: association or causation? Proc R Soc Med 58:295-300.

11. HOHER M, HOMBACH V 1998 Klinische und ökonomische Kosten-Nutzen-Relation bei der Behandlung von Patienten mit koronarer Herzerkrankung. Z Kardiol 87(Suppl 2):8-12.

12. MOGHADASIAN MH, McMANUS BM, FROHLICH JJ 1997 Homocyst(e)ine and coronary artery disease. Clinical evidence and genetic and metabolic background. Arch Intern Med 57:22992308. http://dx.doi.org/10.1001/archinte.1997.00440410025003

13. WELCH GN, LOSALZO L 1998 Homocysteine and atherothrombosis. N Engl J Med 338:1042-1050. http://dx.doi.org/10.1056/NEJM199804093381507

14. STANGER O, HERRMANN W, PIETRZIK K, FOWLER B, GEISEL J, DIERKES J 2003 DACH-LIGA Homocysteine (German, Austrian and Swiss Homocysteine Society): Consensus Paper on the Rational Clinical Use of Homocysteine, Folic Acid and BVitamins in Cardiovascular and Thrombotic Diseases: Guidelines and Recommendations. Clin Chem Lab Med 42(11):1392-1403. http://dx.doi.org/10.1515/cclm.2003.214

15. KHONG TY, HAGUE WM 1999 The placenta in maternal hyperhomocysteinemia. Br J Obstet Gynecol 106:273-278. http://dx.doi.org/10.1111/j.1471-0528.1999.tb08243.x

16. POWERS RW, EWANS RW, MAJORS AK, OJIMBA JI 1998 Plasma homocysteine concentration is increased in preeclampsia and is associated with evidence of endothelial activation. Am J Obstet Gynecol 179:1605-1611.

17. LAVIOURI H, TURPEINEN U, VINIKKA L, YLIKOKALA O 1999 Plasma homocysteine levels elevated and inversely related to insulin sensitivity in preeclampsia. Obstet Gynecol 93:489-493. http://dx.doi.org/10.1097/00006250-199904000-00004

18. RAJKOVIC A, MAHOMED K, MALINOV MR, SORESNON TK 1999 Plasma homocysteine concentrations in eclamptic and preeclamptic African women postpartum. Obstet Gynecol 94:355360. 
19. SORENSON TK, MALINOV MR, WILLIAMS MA, KING IB, LUTHY DA 1999 Elevated second trimester serum homocysteine levels and subsequent risk of preeclampsia. Gynecol Obstet Invest 48:98-103. http://dx.doi.org/10.1159/000010148

20. MAKEDOS G, PAPANICOLAOU A, HITOGLU A, KALOGIANNIDIS I, MALEDOS A, VRAZIOTI V, GOUTZIOULIS M 2007 Homocysteine, folic acid and B12 serum levels in pregnancy complicated with preeclampsia. Arch Gynecol Obstet 275:121-124. http://dx.doi.org/10.1007/s00404-006-0223-2

21. MALINOV MR, RAJKOVIC A, DUELL PB, HESS DI, UPSON BM 1998 The relationship between maternal and neonatal umbilical cord plasma homocysteine suggests a potential role for maternal homocysteine in fetal metabolism. Obstet Gynecol 178:228233.

22. ANDERSSON A, HULTBERG B, BRATTSTROM L, ISAKSSON A 1992 Decreased serum homocysteine in pregnancy. Eur J Clin Chem Clin Biochem 30:377-9.
23. MIGNINI LE, LATTHE PM, VILLAR J, KILBY MD, CAROLLI G, KHAN KS 2005 Mapping the theories of preeclampsia: the role of homocysteine. Obstet Gynecol 105:411-425.

24. ACILMIS YG, DIKENSOV E, KUTLAR AI, BALAT O, CEBESOY FB, OZTURKE, CICEK H, PENCE S 2011 Homocysteine, folic acid and vitamin B12 levels in maternal and umbilical cord plasma and homocysteine levels in placenta in pregnant women with pre-eclampsia. J Obstet Gynaecol Res 37(1):45-50. http://dx.doi.org/10.1111/j.1447-0756.2010.01317.x

25. WHITE WM, TURNER ST, BAILEY KR, MOSLEY TH Jr, KARDIA SL, WISTE HJ, KULLO IJ, GAROVIC VD 2013 Hypertension in pregnancy is associated with elevated homocysteine levels later in life. Am J Obstet Gynecol 09(5):454.e1-7.

26. AKIL A, API O, OTEN CAN E, OZKAN S, ERCAN S, ORCUN A, UNAL O 2015 Does preeclampsia have any adverse effect on fetal heart? J Matern Fetal Neonatal Med 18:1-4. http://dx.doi.org/10.3109/14767058.2015.1085013 